\author{
Abstracta Iranica \\ Abstracta Iranica Revue bibliographique pour le domaine irano-aryen \\ Volume 40-41 | 2019 \\ Comptes rendus des publications de 2017-2018
}

\title{
Yuka Kadoi. "Persia through the Lens: Poetics and Politics of Architectural Photographs in Pahlavi Iran"
}

\section{Sarah Piram}

\section{(2) OpenEdition Journals}

Édition électronique

URL : http://journals.openedition.org/abstractairanica/47902

DOI : 10.4000/abstractairanica.47902

ISBN : 1961-960X

ISSN : 1961-960X

Éditeur :

CNRS (UMR 7528 Mondes iraniens et indiens), Éditions de l'IFRI

\section{Référence électronique}

Sarah Piram, "Yuka Kadoi. "Persia through the Lens: Poetics and Politics of Architectural Photographs in Pahlavi Iran" », Abstracta Iranica [En ligne], Volume 40-41 | 2019, document 1, mis en ligne le 15 juillet 2019, consulté le 27 avril 2021. URL : http://journals.openedition.org/abstractairanica/47902 ; DOI : https://doi.org/10.4000/abstractairanica.47902

Ce document a été généré automatiquement le 27 avril 2021

Tous droits réservés 


\title{
Yuka Kadoi. "Persia through the Lens: Poetics and Politics of Architectural Photographs in Pahlavi Iran"
}

\author{
Sarah Piram
}

\section{RÉFÉRENCE}

Yuka Kadoi. "Persia through the Lens: Poetics and Politics of Architectural Photographs in Pahlavi Iran", Iranian Studies 50, 2017 - Issue 6, p. 873-893, DOI:

10.1080/00210862.2017.1293374

1 C'est en citant le célèbre critique Walter Benjamin (1892-1940) et ses travaux sur la perception de l'art, que Yuka Kadoi introduit son article sur la photographie architecturale en Iran durant l'entre-deux-guerres. Sous le règne de Reza Shah Pahlavi (r. 1925-1941), des efforts de modernisation furent menés dans le pays, si bien que les photographies prises par les voyageurs étrangers furent systématiquement contrôlées : ainsi, comme le souligne l'auteure, il était interdit de révéler un quelconque « mauvais goût » ou une image en opposition avec l'idée même de progrès.

2 Après sa première visite à Téhéran en 1925, l'orientaliste américain Arthur Upham Pope (1881-1969) parvint à obtenir une autorisation du Shah pour accéder aux monuments religieux persans. Sa vision de l'architecture au moyen de la photographie - à travers un objectif - permit de faire connaître et apprécier l'architecture persane au plus grand nombre. En exposant certains de ses clichés à Londres en 1931, au Burlington House, Pope fut à l'origine d'une vision nouvelle de l'architecture persane, notamment de périodes ilkhanide et timouride. Ses photographies, prises dans le mausolée du sultan Uljaitu à Soltaniyeh ou dans celui de Sayyid Rukn al-Din à Yazd, permirent de voir les décors architecturaux autrement, en les assimilant notamment 
aux arts du livre et du textile iraniens. L'auteure montre ainsi que les sources photographiques des années 1920 et 1930 sont aujourd'hui essentielles pour étudier l'historiographie de l'art.

3 Yuka Kadoi termine son article en évoquant les restaurations du patrimoine dans le monde iranien depuis la deuxième moitié du XXe siècle. Certains monuments ont été trop restaurés, elle souligne notamment le cas des monuments timourides de l'Ouzbékistan, dont la connaissance et l'étude peuvent être difficilement approfondies. Il semblerait donc indispensable de se référer aux photographies prises sous le règne de Reza Shah, aujourd'hui parsemées dans différents fonds d'archives. Ces derniers mériteraient, selon l'auteure, d'être réunis et compilés comme une source documentaire majeure pour la préservation des monuments historiques. Les photographies permettraient ainsi de mieux connaître l'état des monuments à une période précise, tout en donnant de véritables pistes d'information pour les restaurations à venir.

\section{AUTEURS}

\section{SARAH PIRAM}

Doctorante en histoire de l'art contemporain, Université Paris-Nanterre 